\title{
PROFIL MOLA HIDATIDOSA DI BLU RSUP PROF. DR. R. D. KANDOU MANADO
}

\author{
Sarah Damongilala \\ Hermie M.M. Tendean \\ Maria Loho
}

\author{
${ }^{1}$ Kandidat Skripsi Fakultas Kedokteran Universitas Sam Ratulangi Manado \\ ${ }^{2}$ Bagian Obstetri-Ginekologi Fakultas Kedokteran Universitas Sam Ratulangi Manado \\ Email: sarahdamongilala@gmail.com
}

\begin{abstract}
Mola Hydatidosa is one of the trophoblast gestasional disease. This disease occured in 1 out of 40 labors in Indonesia. This study aimed to obtain the profile of mola hydatidosa in Prof. Dr. R. D. Kandou Hospital Manado. This was a descriptive retrospective study using the medical records of cases in Obstetric Gynecology Department Prof. Dr. R. D. Kandou Hospital Manado 1 January 2012 - 31 December 2013. The results showed that there were 39 cases of mola hydatidosa during that period. The most frequent cases were 20-29 years old (43.6\%), the third parity (30,8\%), senior high school (59\%), hemoglobin level $<10 \mathrm{~g} / \mathrm{dL}$ $(53,8 \%)$, and treated with curettage procedure (66.7\%).
\end{abstract}

Keyword: mola hydatidosa

\begin{abstract}
Abstrak: Mola hidatidosa merupakan salah satu penyakit trofoblas gestasional. Data di Rumah Sakit di Indonesia menunjukkan 1 kasus mola hidatidosa per 40 persalinan. Penelitian ini bertujuan untuk mengetahui profil mola hidatidosa di BLU RSUP Prof. Dr. R. D. Kandou Manado. Penelitian ini bersifat deskriptif retrospektif dengan menggunakan catatan rekam medik dengan subjek penelitian ialah semua kasus di Bagian Obstetri Ginekologi BLU RSUP Prof. Dr. R. D. Kandou Manado periode 1 Desember 2012 - 31 Desember 2013. Hasil penelitian memperlihatkan 39 kasus mola hidatidosa dengan distribusi terbanyak menurut kelompok umur 20-29 tahun (43,6\%), paritas 3 (30,8\%), pendidikan terakhir pada tingkat SMA (59,0\%), kadar hemoglobin $<10$ g/dL $(53,8 \%)$, dan penanganan terbanyak ialah kuretase (66,7\%).
\end{abstract}

Kata kunci: mola hidatidosa

Pada setiap kehamilan normal hasil konsepsi dapat bertumbuh terus dan dilahirkan sebagai bayi yang cukup bulan, sehat dan sempurna. Kehamilan dapat mengalami gangguan pada perkembangan sehingga terjadi kegagalan kehamilan (reproductive failure), tergantung pada tahap dan bentuk gangguannya. Kegagalan ini bisa berupa abortus, kehamilan ektopik, prematuritas, kematian janin dalam rahim, atau kelainan kongenital. ${ }^{1-3}$

Disamping kelainan-kelainan diatas, ada juga kegagalan kehamilan yang perkembangannya tidak normal, dimana terjadi proliferasi sel trofoblas yang abnormal saat kehamilan, dikenal sebagai penyakit trofoblas gestasional. $^{3}$

Mola hidatidosa merupakan salah satu penyakit trofoblas gestasional yang meliputi berbagai penyakit, yaitu: mola hidatidosa parsial dan komplit, koriokarsinoma, mola invasif, dan placental site trophoblastic tumors. ${ }^{3}$

Frekuensi mola hidatidosa umumnya untuk wanita Asia lebih tinggi (1 per 120 kehamilan) daripada wanita di negara Barat 
(1 per 2.000 kehamilan). Di Indonesia, mola hidatidosa dianggap sebagai penyakit penting dengan insiden yang tinggi. Data di Rumah Sakit di Indonesia untuk mola hidatidosa yaitu 1 per 40 persalinan. Penyebaran masih merata karena sebagian besar data masih berupa hospital based. ${ }^{4-5}$

Di negara-negara Barat kasus mola hidatidosa dilaporkan 1:200 atau 2000 kehamilan. Di negara-negara berkembang 1:100 atau 600 kehamilan. Biasanya kasus mola lebih sering ditemukan pada umur reproduktif dan multipara. Dengan meningkatnya paritas kemungkinan menderita mola akan lebih besar. ${ }^{4}$

Variasi angka kejadian berkaitan dengan faktor predisposisi di tiap daerah. Tingginya insiden mola hidatidosa, komplikasi yang ditimbulkan, serta penyulit seperti preeklampsia, tirotoksikosis, dan emboli paru, mengakibatkan diagnosis mola hidatidosa harus ditegakkan sedini mungkin dan memperhatikan hal-hal yang berkaitan dengan faktor-faktor predisposisi. Masalah dari mola hidatidosa yaitu 20\% dapat mengalami berkembang menjadi tumor trofoblas gestasional. ${ }^{1,6-8}$

\section{METODE PENELITIAN}

Penelitian ini bersifat deskriptif retrospektif yang meninjau data pasien di Bagian Obstetri dan Ginekologi FK Unsrat/BLU RSUP Prof. Dr. R. D. Kandou Manado. Subjek penelitian ialah seluruh data pasien di Bagian Obstetri dan Ginekologi FK Unsrat/ BLU RSUP Prof. Dr. R. D. Kandou Manado sejak 1 Januari 2012-31 Desember 2013.

\section{HASIL PENELITIAN}

Pada penelitian mengenai profil mola hidatiosa di bagian Obstetri dan Ginekologi FK UNSRAT/ BLU RSUP Prof. Dr. R. D. Kandou Manado diperoleh sebanyak 39 kasus (Tabel 1).

Tabel 2 memperlihatkan bahwa kasus mola hidatidosa terbanyak pada kelompok umur 20-29 tahun dengan jumlah penderita 17 orang $(43,6 \%)$.

Tabel 3 memperlihatkan bahwa kasus mola hidatidosa lebih banyak ditemukan pada tingkat pendidikan terakhir SMA dengan jumlah penderita 23 orang (59,0\%).

Tabel 1. Insidens kasus mola hidatidosa di RSUP. Prof. R. D. Kandou Manado

\begin{tabular}{cc}
\hline Tahun & $\begin{array}{c}\text { Jumlah kasus } \\
\text { mola hidatidosa }\end{array}$ \\
\hline 2012 & 23 \\
2013 & 16 \\
Total & 39 \\
\hline
\end{tabular}

Tabel 2. Distribusi kasus Mola Hidatidosa menurut Umur

\begin{tabular}{ccc}
\hline $\begin{array}{c}\text { Umur } \\
\text { (tahun) }\end{array}$ & $\begin{array}{c}\text { Kasus Mola } \\
\text { Hidatidosa }\end{array}$ & $\%$ \\
\hline $20-29$ & 17 & 43,6 \\
$30-39$ & 14 & 35,9 \\
$>40$ & 8 & 20,5 \\
Total & 39 & 100 \\
\hline
\end{tabular}

Tabel 3. Distribusi kasus mola hidatidosa menurut pendidikan

\begin{tabular}{ccc}
\hline Pendidikan & $\begin{array}{c}\text { Kasus mola } \\
\text { hidatidosa }\end{array}$ & $\%$ \\
\hline SMP & 11 & 28,2 \\
SMA & 23 & 59,0 \\
Perguruan Tinggi & 5 & 12,8 \\
Total & 39 & 100 \\
\hline
\end{tabular}

Tabel 4 memperlihatkan bahwa kasus mola hidatidosa lebih banyak ditemukan pada paritas 3 dengan jumlah penderita 12 orang (30,8\%).

Tabel 4. Distribusi kasus mola hidatidosa menurut paritas

\begin{tabular}{ccc}
\hline Paritas & Mola Hidatidosa & $\%$ \\
\hline 0 & 4 & 10,3 \\
1 & 9 & 23,1 \\
2 & 7 & 17,9 \\
3 & 12 & 30,8 \\
$>4$ & 7 & 17,9 \\
Total & 39 & 100 \\
\hline
\end{tabular}

Tabel 5 memperlihatkan bahwa kasus mola hidatidosa terbanyak datang dengan kadar $\mathrm{Hb}<10 \mathrm{~g} \%$ dengan jumlah penderita 21 orang $(53,8 \%)$. 
Tabel 5. Distribusi kasus mola hidatidosa menurut kadar $\mathrm{Hb}$

\begin{tabular}{ccc}
\hline $\begin{array}{c}\text { Kadar Hb } \\
(\mathrm{g} \%)\end{array}$ & $\begin{array}{c}\text { Kasus Mola } \\
\text { Hidatidosa }\end{array}$ & $\%$ \\
\hline$<10$ & 21 & 53,8 \\
$\geq 10$ & 18 & 46,2 \\
Total & 39 & 100 \\
\hline
\end{tabular}

Tabel 6 memperlihatkan bahwa penanganan terbanyak pada kasus mola hidatidosa yaitu kuretase dengan 26 pasien (66,7\%).

Tabel 6. Distribusi kasus mola hidatidosa menurut penanganan dan kemoterapi (Evakuasi jaringan).

\begin{tabular}{ccc}
\hline $\begin{array}{c}\text { Jenis } \\
\text { penanganan }\end{array}$ & $\begin{array}{c}\text { Kasus mola } \\
\text { hidatidosa }\end{array}$ & $\%$ \\
\hline Kuretase & 26 & 66,7 \\
Histerektomi & 8 & 20,5 \\
Evakuasi + & & \\
Kemoterapi & 5 & 12,8 \\
Total & 39 & 100 \\
\hline
\end{tabular}

\section{BAHASAN}

Berdasarkan dari angka kejadian mola hidatidosa di RSUP Prof. Dr. R. D. Kandou Manado terdapat 39 kasus. Insidensi mola hidatidosa di Indonesia umumnya diambil berdasarkan data rumah sakit (hospital based) seperti di RS Dr. Cipto Mangunkusumo Jakarta 1:31 persalinan dan 1:9 kehamilan; Luat Siregar di Medan tahun 1982 11-16 kasus per 1000 kehamilan; RS. Dr. Soetomo (Surabaya) 1 kasus per 80 persalinan; Djamhoe Martaadisoebrata di Bandung 9-12 kasus per 1000 kehamilan. ${ }^{4}$ Pada penelitian sebelumnya yang dilakukan di RSUP. Prof. Dr. R. D. Kandou Manado tahun 2002 ditemukan kasus mola hidatidosa 1:123 kehamilan, dan tahun 2003 ditemukan kasus mola hidatidosa 1:245 kehamilan.

Hasil penelitian memperlihatkan bahwa kasus mola hidatidosa terbanyak pada kelompok umur 20-29 tahun dengan jumlah penderita 17 orang (43,6\%) (Tabel 2). Usia ibu diidentifikasi sebagai risiko tinggi pada mola hidatidosa. Pada penelitian tersebut didapatkan median usia
33 kasus mola hidatidosa 22 tahun dengan usia termuda 18 tahun dan usia tertua 40 tahun. $^{9}$ Hasil penelitian di Universitas Andalas melaporkan kelompok umur yang terbanyak menderita mola hidatidosa ialah 25-29 tahun yaitu sebanyak 17 kasus $(20,73 \%){ }^{10}$ Berdasarkan teori kelompok umur yang memiliki risiko tinggi untuk mendapat mola hidatidosa yaitu mereka yang hamil pada usia dibawah 20 tahun dan di atas 35 tahun. Pada wanita usia $>40$ tahun mempunyai risiko 5-10 kali lebih tinggi untuk mendapat mola hidatidosa dibandingkan wanita yang lebih muda. ${ }^{11}$

Pada penelitian yang telah dilakukan di RSUP Prof. Kandou Manado diperoleh hasil sebanyak 39 kasus mola hidatidosa dan didapatkan pada paritas 3 yaitu sebanyak 12 orang (30,8\%). Hasil yang sama juga didapatkan pada penelitian yang dilakukan di Laboratorium Patologi Anatomi Fakultas Kedokteran Universitas Andalas dimana kasus mola hidatidosa didapatkan terbanyak pada paritas 3 yaitu $(14,63 \%)$ dan pada paritas $\geq 5(12,20 \%){ }^{10,12}$ Seorang ibu yang sering hamil atau melahirkan mempunyai risiko yang lebih tinggi untuk mengalami komplikasi kehamilan dan persalinan. Telah diketahui bahwa penyakit ini banyak ditemukan pada golongan sosial ekonomi rendah, usia 20 dan $>35$ tahun dan paritas tinggi. ${ }^{1-5}$

Tabel 5 memperlihatkan bahwa kasus mola hidatidosa terbanyak mempunyai kadar $\mathrm{Hb}<10$ g\% dengan jumlah penderita 21 orang (53,8\%), dan diikuti oleh kadar $\mathrm{Hb} \geq 10 \quad \mathrm{~g} \%$ dengan jumlah penderita 18 orang (46,2\%). Dari hasil penelitian sekitar 97\% dari kasus mola hidatidosa memiliki perdarahan pervaginam. ${ }^{13}$ Pada penderita dengan mola hidatidosa berdasarkan penelitian Martaadisubrata didapatkan 79 kasus (83\%) dengan nilai $\mathrm{H} \underline{\underline{b}} 7 \mathrm{~g} / \mathrm{dL} .{ }^{14}$ Perdarahan pervaginam merupakan gejala utama dan keluhan tersering pasien mola hidatidosa untuk datang memeriksakan diri. Berhubung kehamilan ini abnormal maka tubuh berusaha mengeluarkannya sehingga terjadi perdarahan pervaginam. ${ }^{13}$

Gejala perdarahan ini biasanya terjadi pada bulan pertama sampai ketujuh dengan 
rata-rata 12-14 minggu. ${ }^{4}$ Perdarahan ini biasanya bersifat perdarahan biasa intermiten, bercak-bercak sedikit, atau sekaligus banyak sehingga pasien menderita anemia bahkan sampai menyebabkan syok dan kematian. Efek dilusi akibat hipervolemia yang cukup berat dibuktikan terjadi pada sebagian wanita yang molanya lebih besar. ${ }^{4}$

Pada hasil penelitian ini jenis penanganan kuretase terbanyak dengan jumlah 26 orang (66,7\%). Tindakan kuretase menjadi pilihan untuk membersihkan rahim dari gelembunggelembung mola.

\section{SIMPULAN}

Dari hasil penelitian di Bagian Obstetri Ginekologi BLU RSUP Prof. Dr. R. D. Kandou Manado periode 1 Desember 2012-31 Desember 2013 dapat disimpulkan distribusi terbanyak menurut kelompok umur 20-29 tahun (43,6\%), paritas $3(30,8 \%)$, pendidikan terakhir pada tingkat SMA (59,0\%), kadar hemoglobin <10 g/dL (53,8\%), dan penanganan terbanyak ialah kuretase $(66,7 \%)$.

\section{SARAN}

Disarankan agar para ibu untuk rutin memeriksakan kehamilan. Ibu yang menikah pada umur kurang dari 20 tahun agar menunda kehamilan hingga pada umur reproduksi yang sehat.

Pentingnya pemberian konseling pada setiap ibu pasca abortus, pasca kuret, pasca mola hidatidosa agar lebih mematuhi jadwal periksa selama 1 tahun.

Perlunya peningkatan gizi terhadap ibu yang sedang dalam masa kehamilan.

Penyediaan sarana pelayanan kesehatan yang memadai dan berkualitas yang dapat dijangkau oleh masyarakat.

\section{DAFTAR PUSTAKA}

1. Cunningham FG, Leveno KJ, Bloom SL, Hauth JC, Gilstrap LC, Wenstrom KD. Williams Obstetric (22nd ed.). New York McGraw-Hill Companies, 2005; p. 274-82.
2. Martaadisoebrata D. Buku Pedoman Pengelolaan Penyakit Trofoblas Gestasional. Jakarta: EGC, 2005.

3. Andrijono. Sinopsis Kanker Ginekologi. Divisi Onkologi, Departemen Obstetri dan Ginekologi. Jakarta: FKUI, 2004; p. 129-34.

4. Fitriani R. Mola Hidatidosa. Jurnal Kesehatan Fakultas Kedokteran UIN Alauddin Makassar. 2009;11(4):1-6.

5. Leveno KJ, Cunningham FG, Gant NF, Alexander JM, Bloom SL, Casey BM, et al. Obstetri Williams PJ (21th ed.). Jakarta: EGC, 2005; p. 24-30.

6. Mochtar R. Sinopsis Obstetri Jilid 1 (Edisi 2). Jakarta: EGC, 1998; p. 238-45.

7. Sastrowinata S, Martaadisoebrata $D$, Wirakusumah FF. Obstetri Patologi (Edisi 2). Jakarta: EGC, 2005: p. 28-35.

8. Manuaba IBG, Manuaba IAC, Manuaba IBGF. Pengantar Kuliah Obstetri. Jakarta: EGC, 2007; p. 728-70.

9. Moore LE, Hernandez E. Hydatiform mole. Available from: http://emedicine.medscape.com/article/ 254657.

10. Mohamed N. Frekuensi mola hidatidosa di Bagian Patologi Anatomi Fakultas Kedokteran Universitas Andalas periode Januari 2003 sampai Desember 2004 [Skripsi]. Padang: Universitas Andalas, 2008.

11. Khrismawan, Saleh ZA, Sanif R, Theodorus. Efficiency of NETDC (New England Trophoblastic Disease Center) Prognostic Index Score to predict gestasional trophoblastic tumor from hydatidiform mole. Med J Indones 2004; 13: 40-6

12. Soekimin. Penyakit trofoblas ganas. Bagian Patologi Anatomi Universitas Sumatera Utara, 2005. Available from URL: http://library.usu.ac.id.

13. Berkowitz SR, Goldstein DP. Gestasional trophoblastic disease. In: Berek JS, editor. Novak’s Gynecology (13th ed.). Philadelphia: Lippincott Williams \& Wilkins, 2002.

14. Martaadisubrata D. Problematik penyakit trofoblas ditinjau dari epidemiologi serta pengelolaanya. Bandung: Universitas Padjadjaran, 1980; p. 1130. 